\title{
AQUISIÇÃO DE UMA LÍNGUA ESTRANGEIRA: UM ESTUDO SOBRE O PROCESSO DE APRENDIZAGEM DE LÍNGUA INGLESA EM UMA ESCOLA DE IDIOMAS
}

\section{ARTIGO ORIGINAL}

BEZERRA, Marta Joelma ${ }^{1}$

ROCHA, Leonardo Manuel das Neves ${ }^{2}$

BEZERRA, Marta Joelma. ROCHA, Leonardo Manuel das Neves. Aquisição de uma língua estrangeira: Um estudo sobre o processo de aprendizagem de Língua Inglesa em uma escola de idiomas. Revista Científica Multidisciplinar Núcleo do Conhecimento. Ano 04, Ed. 09, Vol. 05, pp. 05-21. Setembro de 2019. ISSN: 24480959, Link de acesso: https://www.nucleodoconhecimento.com.br/letras/linguaestrangeira

\section{RESUMO}

O presente trabalho teve como foco de estudo a aprendizagem de Língua Inglesa em uma escola de idiomas, na cidade de Natal, Brasil. Para isso, trabalhamos com dez professores e quarenta alunos de Língua Inglesa, nas unidades da escola de idiomas investigada. O Inglês está em todas as áreas das ciências, nas artes e no mercado de trabalho. Esta pesquisa foi realizada através de observação em salas de aula, conversas informais e questionários com os respectivos professores e alunos, para que pudéssemos detectar como se realiza a aprendizagem destes alunos. Os resultados indicam que os professores têm uma metodologia adequada e oferecem um ensino de qualidade para os educandos. Mais da metade dos alunos pesquisados

\footnotetext{
${ }^{1}$ Graduação em Letras/Língua Inglesa, Especialização em Ensino da Língua Inglesa, Mestra em Ciências da Educação.

2 Doutorado em Ciências da Educação.
} 
possuem um nível de proficiência na Língua Inglesa suficiente para se comunicar no idioma.

Palavras-chave: Metodologias, aprendizagem, Língua Inglesa.

\section{INTRODUÇÃO}

O estudo sobre aquisição de uma língua estrangeira é um tema complexo e pode ser ponderado a partir de múltiplos aspectos, a nossa finalidade é seduzir o leitor a refletir sobre alguns enfoques teóricos e ao mesmo tempo pensar acerca da realidade vivenciada por uma escola de idiomas, cujas unidades de ensino estão localizadas nas Zonas Leste e Sul da cidade de Natal, capital do Estado do Rio Grande do Norte.

Para isso, vamos identificar, por meio de instrumentos de investigação, os fatores que podem estimular o alto desempenho na aquisição da língua inglesa e discutir a prática docente, analisando as teorias que embasam o tema.

Recorremos, assim, ao pensamento de autores como Chomsky (1986a), que afirma haver uma teoria de aquisição de línguas chamada Gramática Universal. Sua principal característica é que cada pessoa supostamente possui esta chamada gramática em sua mente desde o nascimento. Esta gramática universal é um dispositivo na mente das pessoas, necessário para adquirir a linguagem, chamado "Language Acquisiton Device" (LAD). De acordo com este autor, esta gramática é idêntica na mente de cada pessoa.

Por sua vez, Larsen-Freeman \& Celce-Murcia (1999), confirma que na produção de estudantes de segunda língua há processos de transferência de uma língua para outra, supergeneralização, redução, redundância, e diferentes estratégias de comunicação. Sempre há estratégias no aprendizado de qualquer conhecimento, não poderia ser diferente na aprendizagem de uma segunda língua. Muito embora tenha havido inúmeras pesquisas neste campo, Mitchell \& Myles (2002), afirma que estas têm avançado bastante somente nas duas últimas décadas, e chegaram à compreensão do processo de aquisição de segunda língua. 
Sabemos que a citada escola é uma franquia de uma escola de idiomas, portanto nesta não há evasão, baixa frequência às aulas ou repetência porque é um investimento alto financeiramente, e os alunos tendem a buscar um alto desempenho, para poder desenvolver satisfatoriamente as competências e habilidades que o estudo de outro idioma exige.

Diante disso, resolvemos investigar a situação no sentido de obter possíveis retornos para os seguintes questionamentos:

1 - Qual a importância da aquisição de uma língua estrangeira?

2 - Como acontece o processo cognitivo na aquisição de uma língua estrangeira segundo as teorias existentes?

3 - Qual o nível de proficiência linguística dos estudantes de escolas de idiomas?

4 - Qual o tipo de insumo de Inglês ao quais os sujeitos têm acesso nas aulas?

5 - Como os sujeitos são instigados pelos professores a aprender inglês?

6 - Qual o uso que os alunos fazem da língua Inglesa?

7 - Como os sujeitos reagem às aulas de Inglês?

8 - Quais os prós e os contras do ensino de Inglês nas escolas de idiomas?

Apreendemos que as perguntas supracitadas caracterizam os pontos gerais de nossa pesquisa sobre aquisição de língua estrangeira, como é um fato que a língua inglesa tem se estendido e se tornado uma língua internacional, decidimos enfatizar que a aprendizagem de pelo menos uma língua estrangeira pode trazer nada mais que benefícios para quem a adquire ou a estuda. 


\section{DESENVOLVIMENTO}

A partir dos anos de 1970, os estudos sobre língua estrangeira, foram inseridos na área da Linguística Aplicada. A partir de então, os estudos a respeito do ensino e aprendizagem de línguas, no Brasil, passaram a mudar o seu foco, fomentando inicialmente o estudo de textos para poder partir para a produção de narrativas e descrições de acordo com as necessidades dos estudantes.

De acordo com Castro (1998), algumas teorias foram elaboradas em relação à aquisição da língua estrangeira. A autora faz um apanhado sobre as pesquisas publicadas até então, e enfatiza que certas teorias que estudam a aquisição da linguagem consideram a primeira língua como um objeto concretizado, partindo da primeira língua como estudo para a segunda, conforme defende

Não seria exagero dizer que, frequentemente, considera-se a língua materna - em certas teorias em Aquisição de Linguagem e, sobretudo nos estudos em aquisição de uma segunda língua - como um objeto cuja realidade parece certa e precisa. Quase sempre exclusivamente definida no eixo de uma cronologia, ela é aí reconhecida como primeira língua. Castro (1998, p. 135)

Esta pesquisa é de natureza teórico-empírica, baseia-se em bibliografias e dados coletados em campo. Apresenta alguns dados estatísticos, porém esta é uma pesquisa de abordagem quantitativa/qualitativa, uma vez que descreve, o mais detalhadamente possível o processo de aprendizagem de Língua Inglesa de alunos de cursinhos de idiomas na cidade de Natal-RN.

A pesquisa tem como objetivo geral:

Descrever as competências que a aquisição de língua estrangeira desenvolve nos aprendizes.

Os objetivos específicos são:

- Caracterizar a importância da aquisição de Língua Inglesa no mundo contemporâneo; 
- Descrever as teorias e estratégias sobre a aprendizagem de línguas.

- Delinear o trabalho docente e os resultados da aprendizagem de alunos de língua inglesa em escolas de idiomas.

A atual investigação é limitada apenas a escolas de idiomas, pois voltamos a enfatizar que o objetivo deste trabalho é investigar as competências desenvolvidas nos alunos no processo de ensino aprendizagem de Inglês. Escolhemos escolas de idiomas pelo sucesso atribuído às mesmas. Não poderíamos conseguir falantes de língua estrangeira na escola de ensino regular. Assim sendo, a corpora levantada neste estudo não representa necessariamente a aprendizagem de inglês nas escolas de educação normal. Percebe-se que a aprendizagem deste idioma em cursinhos obtém resultados significativos em termos de rendimento e desempenho dos estudantes.

Conforme os dados obtidos, constatamos que na escola de idiomas estudada, a maioria dos professores é do sexo masculino, com ressalva de três professores, que estão acima de 30 anos, os demais têm idade entre 20 e 29 anos, o que comprova um corpo docente bastante jovem na escola, e em conversas informais com alguns deles, com muitas ideais para pôr em prática. Em relação ao tempo de magistério, com exceção de apenas um professor, todos os demais ensinam de 6 meses a 1 ano e meio, ou seja, não há docentes cansados da profissão, pois estão nesta há bem pouco tempo.

Percebe-se que $100 \%$ dos professores pesquisados já viajaram ou moraram algum tempo em outro país, o que é extremamente benéfico pessoalmente e profissionalmente. Viajar ou morar em outro país é uma experiência que acrescenta muito aprendizado na vida de qualquer pessoa, especialmente quando esta é um professor de idiomas.

Compreende-se que não existe algo mais enriquecedor e prazeroso no que diz respeito à versatilidade no mundo do trabalho do que viver o cotidiano em um país estrangeiro. Se conviver no exterior já era um conhecimento que agregava muito aprendizado cultural a qualquer profissional, atualmente, com a não existência de 
confins graças às TIC, habituar-se em outro país é um fator diferencial para um currículo ou para um candidato em processo seletivo.

Segundo os professores, a maioria dos estudantes mostra-se interessada. Isto devese ao dinamismo das aulas e sempre com muita conversação, jogando com situações do dia a dia. As aulas são sempre em inglês, ou seja, há uma imersão na cultura do idioma alvo, enquanto em sala de aula. Com a metodologia bastante interativa mais o uso de tecnologia e professores supertreinados, os alunos se envolvem nas aulas. De acordo com o depoimento de P4:

"Você começa a entender e a falar inglês no primeiro dia de aula."

O teor gramatical é expresso de forma contextualizada e significativa. O aluno é instigado a discorrer e a proclamar suas próprias ideias, categoria básica para se alcançar o domínio do idioma, evitando-se desta forma a pura e simples memorização.

De fato, se os docentes partirem do pressuposto de que todo aprendiz quer aprender, mesmo quando essa vontade está escondida no inconsciente, então pode completar que deve apresentar o máximo de atividades cativantes para que o discípulo adquira o aprendizado. A ausência de atividades prazerosas que acordam o desejo pelo conhecimento nos cursos começa a ter efeitos quando o aluno começa a perder a vontade intrínseca de querer aprender, que com o passar do tempo torna-se um enfado.

A conduta dos estudantes pode, em seguida, ter decorrências graves não só para o próprio aluno como para a sociedade, entre elas, a violência, a criminalidade e até mesmo implicação com drogas. "A indisciplina é uma das maiores dificuldades enfrentadas pelos professores para desenvolverem o trabalho pedagógico". ParratDayan (2008, p. 21). As habilidades de gerir, de dirigir e de supervisionar os alunos durante o processo de aprendizagem são os componentes indispensáveis para um ensino e aprendizagem eficazes.

Percebe-se que na escola estudada, todo o trabalho é desenvolvido coletivamente, não há casos de anarquia. Há bastante diálogo, estudo e cooperação, instrumentos 
utilizados que serve de meio na busca na disciplina que considera o respeito como condição principal nas relações existentes na escola.

Conforme Parrat-Dayan (2008) "[...] é mais eficaz se aproximar calmamente de um aluno e pedir para retomar seu trabalho que chamar a sua atenção em voz alta na frente de todos". [...]. (p. 64).

A escola pesquisada apresenta uma aprendizagem significativa, por utilizar, acima de tudo, uma expectativa interacionista, para o preparo dos dados, no qual a pessoa é firmemente provocada pela realidade. O Sistema Educativo deverá ter sempre como escopo o desenvolvimento das pessoas, de forma completa e, simultaneamente, que as conduza à sua realização pessoal.

A intenção é que o estudante esteja hábil a se comunicar com eficiência com os nativos da língua fluentemente. Além disso, em sua etapa de concepção geral, o curso: Ensina o aluno a pensar em inglês; capacita o aluno a se comunicar em inglês em situações práticas comuns do cotidiano de pessoas comuns.

Não se aborda aqui o privilegiar da gramática ou as funções comunicativas, mas de requerer a ciência e a importância de si e do outro, traduzido em diferentes formas de esclarecimento do mundo, concretas nas atividades de produção oral e escrita.

Arguimos aos docentes o tempo proposto para cada conteúdo. Segundo os mesmos, obtivemos as seguintes assertivas:

P4 "O aprendizado é contínuo".

P7 "It depends on the student. There are students who pick up the same day."

Através destes excertos percebe-se que os professores têm diferentes apreciações a respeito, mas em suma, todos tem um respeito pelo estudante. P7 enfatiza que se deve respeitar o ritmo de aprendizagem de cada um. A fim de defender a hipótese de que não existe ritmo de aprendizagem, afirmamos que o que existe são arquivos mais ou menos recebidos nos diagramas intelectuais dos aprendizes e que é a qualidade 
deste material arquivado que é determinante na ação da aprendizagem e não o tempo vivido ou a qualidade em que ele foi coletado.

Em relação ao ritmo de aprendizagem Madalena Freire (2003) afirmou que as letras nos conceituam.

O aprendizado do registro é o mais poderoso instrumento na construção da consciência pedagógica e política do educador, pois, quando registramos, tentamos guardar, prender fragmentos do tempo vivido que nos é significativo, para mantê-lo vivo. Não somente como lembranças, mas como registro de parte da nossa história, nossa memória. (p. 6).

Conforme Grossi (1998) é muito cômoda a situação na qual vivemos, uma vez que temos o direito de viver depois de Piaget, de Vygotsky, de Wallon, de Paulo Freire, entre outros, criadores estes que ministraram dados expressivos para a compreensão de como ocorre a aprendizagem e nos deixam com muitas vantagens para tentarmos entender este complexo fenômeno. Antes deles, expúnhamos apenas duas compreensões para explicar o conhecimento - o inatismo e o empirismo, sendo que a ideia de ritmo de aprendizagem, anterior a estes teóricos, é tipicamente inatista, pois

...nesta concepção, a aprendizagem tem uma velocidade que está associada à idade, à maturação, ao desenvolvimento "natural", a uma evolução quase biológica, o que justifica a organização das turmas por faixa etária e a expectativa de que, inclusive com mecanismos aceleratórios, os alunos acedem ao que seria próprio à sua faixa etária - o que está embasando a ideia dos ciclos. (Grossi 1998, p. 9)

$\mathrm{Na}$ aprendizagem interferem aspectos afetivos e relacionais, além dos cognitivos e estas não se instalam no vazio e nem à margem de outras aptidões. É preciso que tenham significado para o aprendiz, pois se não tiver logo se perde em pensamentos ou conversas paralelas à aula. Quando aprende, o aprendiz se implica globalmente nesta tarefa, e o processo, bem como seu resultado, repercute globalmente.

A afabilidade pode até abrandar o conhecimento, mas pode também fortalecê-lo, pois existe uma relação estreita entre inteligência e afetividade: a dificuldade de raciocinar pode ser amortecida, ou mesmo destruída, pelo déficit de emoção ou pelo seu 
excesso, podendo gerar mecanismos de defesa e levando à intervenção na aquisição do conhecimento.

Consideramos indispensável apreciar genuinamente a metodologia de ensino utilizada. Para isso, perguntamos aos professores sobre seus métodos de ensino e destacaremos a seguir algumas respostas.

P2 "A metodologia da escola".

P3 "Utilizo a metodologia da repetição dos conteúdos, logo em seguida a contextualização com a realidade".

Refletir sobre método de ensino é um palco com muitas variáveis. Mas aqui, apreendemos que os catedráticos abordados afirmam utilizar a tecnologia da escola. A qual tem como base a abordagem comunicativa. Este approach está sedimentado no princípio de que a segunda língua é aprendida por meio da comunicação. Aprendese melhor a língua estrangeira quando o aluno tenta comunicar algo que realmente deseja ou precisa dizer.

No enfoque comunicativo, todas as quatro capacidades linguísticas de leitura, escrita, compreensão auditiva e fala são praticadas e desenvolvidas. São empregadas técnicas de modo que as habilidades de leitura, escrita e compreensão auditiva sejam utilizadas como suporte para a habilidade mais importante: a fala.

Para entender o uso do idioma, o aluno necessita analisar a língua dentro de um contexto. As aulas permitem que o aluno seja exposto à linguagem em situações de modo que ele estabeleça uma relação pessoal com o assunto. Os professores animam o aluno a ser mais ativo nas aulas, por meio de discussões e comentários sobre tema, antes da explicação formal ser apresentada.

Comumente, os educandos medem sua desenvoltura linguística em "quanto podem falar". Na escola examinada, o aluno principia a falar desde a aula inicial, com atividades de áudio e leitura unificadas para animar o diálogo, de modo que ele possa arquitetar significados com respostas adequadas, em contextos de situações reais. 
Ou seja, as aulas apresentam situações similares às da vida real (real life situations). O objetivo é prepara-los para situações reais, seja para o trabalho ou na vida pessoal.

É notável que nesta escola predomina a ênfase na variante do inglês americano. É importante perceber que a língua inglesa, já há um bom tempo, deixou de ser propriedade dessa ou daquela nação, desse ou daquele país, porém ainda há uma hegemonia da variante americana. Como bem diz Widdowson (2003), uma língua como o Inglês só pode ser caracterizada como internacional pelo fato de ter deixado de ser o monopólio de uma nação. "It remains an internationally intelligible means of communication quite simply because the community that uses it is international". (p. 45)

Ou seja, em sua condição de língua internacional, aquilo que chamamos de "World English" expressão usada por Rajagopalan, (2004, 2005a, 2005b) não tem falantes "nativos", isto é, de acordo com a cartilha vigente. É extraordinário frisar que o "World English" não exclui ninguém, muito menos aqueles que se acham seus únicos donos. Dessa forma, o inglês, segundo Cruz (2006 apud Pereira, 2010, p. 47) "refere-se ao Inglês usado nas interações entre falantes não nativos que têm línguas maternas diferentes".

Híbrida é a marca registrada dessa nova "língua" (ou, acontecimento linguístico). Outro atributo do inglês atualmente é o que Blommaert, Collins e Slembrouck (2005) delineiam como multicentricidade, isto é, a experiência de múltiplos centros, e consequentemente, múltiplas normas. No multilingualismo, defendido por estes autores, vemos que isto é fruto da globalização, através da qual alegam "Issues of globalization, and more particularly with the question of the production of locality under conditions of globalizations." (p.230).

O Próprio autor explicita que o primeiro círculo são os falantes dos Estados Unidos, Grã-Bretanha, Canadá, Austrália e Nova Zelândia. Os falantes do segundo círculo seriam os povos da Índia, África Ocidental e África Oriental. E o terceiro grupo pertence aos falantes de Inglês como língua estrangeira, dentre esse grupo estariam os povos da China, Japão, Grécia e Polônia. 
Diante desta nova realidade, questionamos se as metodologias utilizadas são eficientes para o ensino das quatro habilidades na língua estrangeira. Citaremos respostas de alguns dos professores pesquisados.

P2 "Desde que o aluno preste atenção às aulas os métodos são eficientes".

P9 "Sim, a metodologia é eficiente, porém é de extrema importância os alunos dedicarem tempo e vontade para o aprendizado".

Segundo os professores a metodologia do curso é eficiente no ensino das quatro habilidades do idioma-alvo, porém é preciso a contrapartida do alunado. Sem o esforço de cada um pela sua própria aprendizagem não há progresso. Os professores reforçam a autodisciplina que o aprendiz deve ter com o seu aprendizado.

Para conseguir elevar ao máximo as próprias potencialidades e minimizar o tempo despendido com estas tarefas, cada aprendiz deve, sobretudo, ter um plano de estudo bem ilustrado para o seu próprio uso. E acima de tudo, a disposição e a disciplina são dois fatores baseais nos estudos.

O questionário foi lançado para os alunos do curso de inglês, para que tivéssemos uma amostra precisa sobre a aprendizagem e interesses dos alunos.

A maioria dos alunos que responderam foi do sexo masculino, ou seja, $52 \%$, contra $48 \%$ do sexo feminino.

Essas percentagens confirmam que na escola de idiomas investigada, o contingente maior é de alunos, contrariando uma tendência das escolas brasileiras de ensino regular que contam com um comparecimento expressivo de estudantes do sexo feminino.

Os homens só excedem as mulheres na faixa etária mais alta, 60 anos ou mais, quando eles declararam estudar 4,6 anos, enquanto as mulheres ficam com apenas 4,3 anos de estudos, este fato se deve à época em que estas viveram e o acesso que tinham à escola. 
Quanto à faixa etária dos entrevistados, ressaltamos que a maioria é formada por jovens, na faixa etária entre 11 e 20 anos, enquanto a somatória dos alunos com idade de 21 anos em diante chega a $25 \%$, confirmando o fato de que o aluno que se dedica a aprender outro idioma em cursinhos que geralmente exigem um alto poder aquisitivo são jovens que ainda não entraram no mercado de trabalho.

Como a pesquisa da cognição da língua inglesa é evidente a importância de sabermos o nível de aprendizado do idioma-alvo dos estudantes. O resultado obtido foi que $45 \%$ entendem quase tudo e até conseguem trocar ideias. $25 \%$ entendem, mas não sabem o suficiente para conversar.

Somente $23 \%$ dos alunos responderam entender tudo no idioma alvo e falar fluentemente. Isto comprova que não basta a escola ter uma boa metodologia aliada a bons professores, o exercício está sujeito principalmente à vontade e disciplina do aprendiz. Para ter um alcance real do idioma é necessário que o aluno tenha em mente que o início de tudo é aprender a aprender, tem que buscar em si mesmo e por si mesmo a motivação imperiosa para a aprendizagem.

De acordo com os entrevistados a grande maioria enfatiza a carreira e viagens como os principais motivos pelos quais vale a pena aprender outra língua. Em seguida, a cultura também foi enfatizada. Entende-se que os aprendizes conhecem a importância no mundo do trabalho em relação à aprendizagem da língua inglesa. Na verdade, a praticidade de resolver circunstâncias rotineiras ratifica a função crucial que a língua inglesa detém na contemporaneidade.

Com a unificação do exercício do inglês nas corporações do mundo todo, as culturas, termos técnicos e linguagens se fundem cada vez mais e todas as companhias falam praticamente a mesma língua, independentemente da localidade no planeta, há o predomínio do inglês. Por isso, há ininterruptamente um desígnio latente de quem aprende outro idioma de visitar pelo menos um dos países que fale a língua que se estuda. 
Dos alunos entrevistados, $82 \%$ assistem a filmes ou desenhos animados com o áudio ou legendas em inglês como metodologia pessoal no aprendizado do idioma. É inteiramente possível e recomendável que se aprenda inglês através de filmes. $\mathrm{O}$ professor pode se utilizar deste mecanismo e o próprio aprendiz deve escolher uma forma prazerosa de aprender.

É inegável que as novas técnicas ajudam aos alunos que a elas tem acesso a melhorar em seu processo cognitivo. Aliás, estes recursos tecnológicos, as famosas TIC, desenvolvem no aprendiz a motivação imperativa para tomar posse da construção e aprimoramento dos seus conhecimentos na língua em estudo.

A música é, comprovadamente, um dos mais prazerosos ambientes para o aprendizado em qualquer área do conhecimento. Estudar com música é muito prático, porquanto incita o ser humano à alma, à emoção, fazendo com que os estudantes se desliguem de tudo aquilo que no momento está prejudicando mentalmente. Os alunos entrevistados, em sua maioria, estão na adolescência.

Somente $37 \%$ dos entrevistados leem livros em inglês, apesar da biblioteca da escola possuir um acervo abundante. Para se aprender outro idioma, se faz necessário muita inclinação por parte do aluno. Não há aprendizagem, se o aluno não estiver interessado. É possível que este seja um dos ensejos de termos entre os entrevistados apenas $23 \%$ de aprendizes com fluência no idioma.

$\mathrm{O}$ ato de interpretar uma leitura em outro idioma proporciona a possibilidade de uma livre participação social do homem na sociedade, transcendendo de forma reflexiva, crescendo progressivamente e expandindo o seu entendimento das coisas que o cercam e agindo sobre elas. Nesse aspecto, a leitura representa um aparelho de grande poder nas mãos daqueles que a apreendem.

Continuando o nosso questionário, perguntamos aos alunos se os mesmos conversam em inglês com brasileiros e se dialoga em inglês com nativos como parte complementar do seu aprendizado. Como resultado, 52\% conversam em inglês com brasileiros, mas apenas $30 \%$ conversam com nativos da língua inglesa. 
Como nem todos tem uma fluência perfeita na língua, alguns alunos sentem-se travados para falar em inglês e exercitar a sua prática. Sabemos que para falar outro idioma, não basta um léxico, e ciência da gramática e do sotaque. Tornam-se imperativos os conhecimentos peculiares da língua, dos coloquialismos e das expressões idiomáticas, elocuções, phrasal verbs e ditados de uso corrente, que se traduzidos ao pé da letra perde o sentido. Nenhuma língua seria rica sem as suas expressões idiomáticas. Elas são imperativas para falar e escrever bem.

Em uma sociedade letrada, de acordo com Penny Ur, "é como se a fala incluísse todos os tipos de conhecimento". (1996, p. 120). Falar uma língua estrangeira é, então, a aptidão almejada pela maioria dos alunos de línguas. Habilidade esta que requer tenacidade, muita força de vontade, calma e dedicação, para ser desenvolvida, além de diversos fatores que interfere ou intervém no aprendizado.

No mundo de hoje há dois tipos de motivação para o aprendizado: a de si mesmo e a do mercado de trabalho. A primeira parte do educando, de seu anseio, de sua vontade de aprender. Enquanto que a segunda, vem da obrigação externa de aprender, que podem ser: passar em exames, em concursos, seleções, conseguir um bom emprego, ter a oportunidade de viajar para uma região onde se fala a língua-alvo. Por fim, das questões que abordamos somente a questão sobre a aquisição de vocabulário, obteve $100 \%$ de retorno positivo.

Todos os entrevistados responderam sempre buscar adquirir novos vocábulos. Aprender novo vocabulário em inglês é uma ótima maneira de estudar a língua porque as palavras formam blocos de linguagem e através dela expressamos nossos pensamentos. De acordo com a nossa entrevista, a maioria dos aprendentes usam todas as técnicas ao alcance. Desde leituras em inglês até ver filmes e séries para aperfeiçoar a compreensão oral e visual. Da escuta de canções para aperfeiçoar a parte oral até o uso de jogos que ajudam a ativar a memória. Com estas técnicas os aprendizes que se esforçarem adquirirão as quatro habilidades exigidas. 


\section{CONCLUSÕES}

Fizemos uma consulta bibliográfica relacionada ao tema estudado. E também foi de essencial importância as informações dos professores e estudantes da escola, objeto de nossa pesquisa, que apresentaram, através dos questionários, suas respostas e opiniões, os quais se transformaram em dados que cooperaram expressivamente para responder as questões desta pesquisa e confirmar ou não as presunções alçadas.

Verificou-se que a escola oferece um ensino no qual o aluno tem contato com a cultura dos países da língua estudada, pois a grande maioria dos estudantes possui uma formação de conhecimento geral, especialmente um mergulho na cultura da língua inglesa. Assim, ao concluir o curso, o aluno sente-se com mais confiança de uma qualificação melhor para enfrentar o mercado de trabalho, bem como servir de apoio para afrontar novos horizontes e se enraizar mais nos estudos posteriores.

A escola também funciona com um quadro de excelentes professores com um alto domínio da língua que ensinam. Através destes docentes os alunos têm acesso aos conteúdos importantes para a sua formação.

As justificativas em comum assinaladas por docentes e educandos para 0 alto desempenho estão pautadas, entre outros pontos, à atuação pedagógica, especialmente quando ela consegue atender às perspectivas do aluno também a fatores econômicos, já que estes alunos não têm atividade ocupacional que possa limitar o tempo para estudos.

Além do alto desempenho, notamos que a boa frequência, explicada incialmente, devido ao custo da reposição das aulas, contribui também para que o aluno tenha mais empenho na busca pela aprendizagem, pois desta forma ele não deixa de ter acesso ao conteúdo sistematizado diariamente, como também não perde a chance de arquitetar seu conhecimento em parceria com seus pares.

Portanto, se o aluno do cursinho dispor de força de vontade, aprende a língua que deseja, pois, as aulas são muito lúdicas, acontecendo uma verdadeira aprendizagem 
nos conteúdos expostos, os alunos já se comunicam em inglês durante toda a aula, enfim, exerce o seu direito de se comunicar na língua alvo.

Assim sendo, esta investigação nos fez ter uma nova visão a respeito do tema aqui abordado, pois percebemos que mesmo assistindo aulas de inglês durante toda a vida escolar é insuficiente para aprender este idioma se não tiver a oportunidade de fazer um cursinho numa escola de idiomas, com um número pequeno de alunos por turma, para que o professor possa oferecer um atendimento mais individualizado, com professores e metodologias adequadas, ou a experiência de um intercâmbio. Concorrendo para isso também a idade a que se propõem a adquirir a língua-alvo.

Comprova-se que tanto os autores que defendem a teoria inatista não estavam errados, tampouco os que defendem a aprendizagem em exposição ao meio ambiente também não. Todas as línguas são passíveis de aquisição e aprendizagem dependendo apenas da situação do aprendiz e de ambiente favorável.

\section{REFERÊNCIAS}

BLOMMAERT, J., COLLINS, J. AND SLEMBROUCK, S. (2005). Spaces of multilingualism. Language and communication. 25: 197-217.

CASTRO, M. F. P. (2005). Sobre o (im) possível esquecimento da língua materna. Os evangelhos: nas ondas da palavra. Campinas: Editora Academia Estadual de Linguística.

CELCE-MURCIA, M. \& LARSEN-FREEMAN, D. (1999). The grammar book: An ESL/EFL teachers course. 2nd edition. Boston: Thomson Heinle.

CHOMSKY, N. (1986a). Knowledge of Language: Its Nature, Origin and Use. New York: Praeger.

FREIRE, Madalena. (Org.) Sobre rotina: construção do tempo na relação pedagógica. Cadernos de Reflexão - Sobre rotina: construção do tempo na relação pedagógica. São Paulo: Espaço Pedagógico, 1998. p. 43 - 46. 
GROSSI, E. (1998). Ensinando que todos aprendem. In: Revista do GEEMPA, oo 6: Ensinando que todos aprendem, Porto Alegre: Edelbra Indústria Gráfica, (p. 3-9).

LIMA, D. C. (2009). Ensino e aprendizagem de língua inglesa: conversas com especialistas. São Paulo: Parábola Editorial, pp. 43-153.

MITCHELL, R., \& MYLES, F. (2002). Second language learning: concepts and issues. In C. Candlin \& N. Mercer (Eds.), English language teaching in its social context: a reader (pp. 417). London: Routledge.

PARRAT-DAYAN, S. (2008). Le travail enseignant au quotidien. Tradução: ADOUE, Sílvia Beatriz, JUNCAL, Augusto. Como enfrentar a indisciplina na escola. Contexto. São Paulo - SP.

PENNY UR (1996). A course in language teaching: practice and theory. Cambridge: Cambridge University Press.

WIDDOWSON, H. G. (2003). Defining issues in English language teaching. Oxford: Oxford University Press.

Enviado: Agosto, 2019.

Aprovado: Setembro, 2019. 